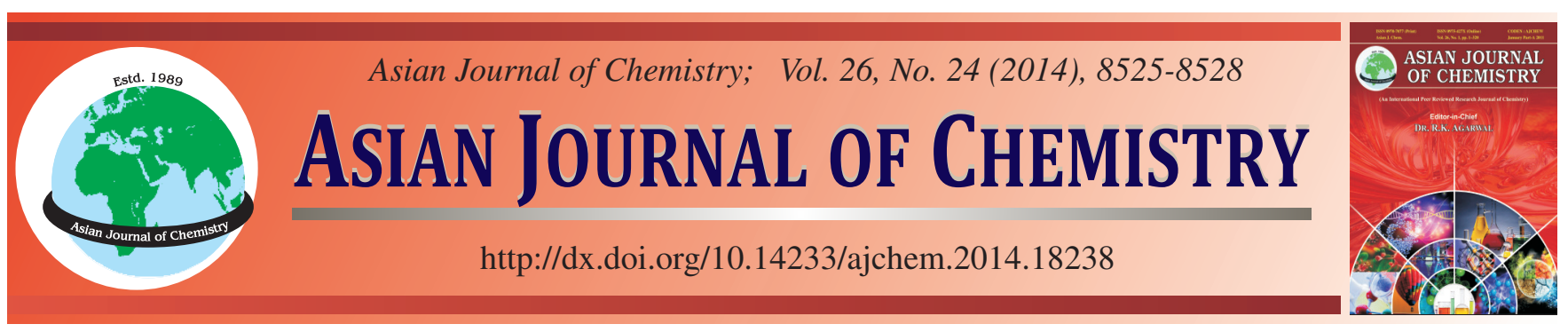

\title{
Oxidative Degradation of Reactive Violet 1 Dye by Ultraviolet Radiation in Presence of Hydrogen Peroxide
}

\author{
Majid Muneer ${ }^{1, *}$, Fazal-ur-Rehman $^{2}$, IJaz A. Bhatti ${ }^{3}$, Nosheen Aslam ${ }^{2}$, \\ Muhammad Asghar Jamal ${ }^{1}$, Muddassar Zafar ${ }^{4}$ and Muhammad Kaleem Khosa ${ }^{1}$
}

${ }^{1}$ Department of Chemistry, Government College University, Faisalabad, Pakistan

${ }^{2}$ Department of Applied Chemistry and Biochemistry, Government College University, Faisalabad, Pakistan

${ }^{3}$ Department of Chemistry, University of Agriculture, Faisalabad, Pakistan

${ }^{4}$ Pir Mehr Ali Shah Arid Agriculture University Rawalpindi, Pakistan

*Corresponding author: E-mail: majid.chemist@yahoo.com

Received: 2 June 2014;

Accepted: 8 August 2014;

Published online: 1 December 2014;

AJC-16395

\begin{abstract}
Degradation of synthetic dye reactive violet 1 in aqueous media having concentrations $10-50 \mathrm{mg} / \mathrm{L}$ has been carried out by UV radiation in presence of $\mathrm{H}_{2} \mathrm{O}_{2}$. The change in colour intensity at $\lambda_{\max } 545 \mathrm{~nm}$ and chemical oxygen demand reduction was examined to evaluate the decrease in organic matter. The decrease in colour intensity was found 18,25 and $100 \%$ while chemical oxygen demand reduction up to 15,25 and $55 \%$ when solutions were treated by $\mathrm{UV}, \mathrm{H}_{2} \mathrm{O}_{2}$ and $\mathrm{UV} / \mathrm{H}_{2} \mathrm{O}_{2}$, respectively. The radiolytic end products were identified by FTIR and GC-MS, which revealed that advanced oxidation process had achieved the complete mineralization. The effect of different operational parameters such as initial dye concentration, UV irradiation time and concentration of hydrogen peroxide on degradation efficiency has also been evaluated. This treatment can be extended to dye containing industrial wastewater.
\end{abstract}

Keywords: Reactive violet, Radiolytic degradation, FTIR, GC-MS.

\section{INTRODUCTION}

It is generally observed that the effluents outcome from dyes manufacturing and textile processing industries is of intense colour due to ineffective treatment methods before being discharged. These effluents not only reduce transparency but also cause damage to the surface and underground water which impose adverse effects on human health. The abundantly complex feature of dye processing effluents contain high colour and chemical oxygen demand (COD) resulting into serious environmental issues ${ }^{1-3}$. Due to ineffectiveness of conventional treatment methods, there is need for an innovative method to treat the persistant pollutants such as synthetic dyes dissolves in aqueous media. Advanced oxidation process using UV light in presence of $\mathrm{H}_{2} \mathrm{O}_{2}$ is an effective treatment technology for the generation of powerful oxidant such as hydroxyl radical to treat the dyes as a model system as well as industrial effluents $^{4}$. The advanced oxidation process using UV radiation and $\mathrm{H}_{2} \mathrm{O}_{2}$ which are characterized by the generation of hydroxyl radicals, the short lived and highly reactive chemical species that react non- selectively with organic substance in wastewater. The possible reactions which occur during $\mathrm{UV} / \mathrm{H}_{2} \mathrm{O}_{2}$ process are hydrogen abstraction, electrophilic addition and electron transfer reactions. This technique has also several advantages over the other treatments such as no sludge formation, operative at ambient temperature, oxygen formed during process and the final products are $\mathrm{CO}_{2}, \mathrm{H}_{2} \mathrm{O}$ and low molecular weight aliphatic carboxylic acid ${ }^{5,6}$.

In the established literature no study has been reported for reactive Violet 1 dye with the help of $\mathrm{UV} / \mathrm{H}_{2} \mathrm{O}_{2}$. In the present study advanced oxidation process have been carried out for the treatment of Reactive Violet 1 dye having concentration $10-50 \mathrm{mg} / \mathrm{L}$. The effect of UV radiation exposure time, $\mathrm{H}_{2} \mathrm{O}_{2}$ concentration and combined effect of $\mathrm{UV}$ and $\mathrm{H}_{2} \mathrm{O}_{2}$ have been evaluated, however the end products were also studied by FTIR and GC-MS.

\section{EXPERIMENTAL}

The reactive Violet 1 dye was provided by Haris dyes and Chemicals (Pvt.) limited, Faisalabad, Pakistan. The commercial dye powder was used without prior purification. The chemicals used during the experiment such as ethyl acetate, potassium dichromate, ferrous ammonium sulphate, hydrogen peroxide, sodium hydroxide and sulphuric acid were of analytical grade 
(Merck, Germany). The triply distilled water was used for the preparation of different concentrations of dye $10-50 \mathrm{mg} / \mathrm{L}$ and other solutions used during study.

Treatment of samples: The aqueous solutions of dye were treated by batch UV photo reactor emitting radiation having wavelength of $254 \mathrm{~nm}$ and 180 watt intensity in the presence and absence of $\mathrm{H}_{2} \mathrm{O}_{2}$ for different time interval (20-60 min). The combined effect of $\mathrm{H}_{2} \mathrm{O}_{2}$ and UV was also studied by adding different concentrations $(2-10 \mathrm{mM})$ of $\mathrm{H}_{2} \mathrm{O}_{2}$ and irradiating dye solutions for optimum time.

Analyses: The dyes samples were analyzed by using (U2001 Hitachi) double beam UV-visible spectrophotometer before and after treatment in order to find their $\lambda_{\max }$ and then change in absorbance at this $\lambda_{\max }$. Chemical oxygen demand (COD) was determined by open reflux method using standard potassium dichromate and ferrous ammonium sulphate and the $\mathrm{pH}$ was measured by $\mathrm{pH}$ meter (Hanna HI 9813).

GC-MS and FTIR analyses: Gas chromatography mass spectrometry (GC-MS) and Fourier transform infra red (FTIR) analyses were performed in order to identify the degraded end products. Prior to analyses, the irradiated samples were extracted with redistilled ethyl acetate. The organic phase was decanted followed by dehydration with $\mathrm{MgSO}_{4}$ for $24 \mathrm{~h}$. The samples concentrated by rotatory vacuum evaporator and stored for further analysis? ${ }^{7}$.

\section{RESULTS AND DISCUSSION}

Effect of UV radiation on absorbance and reduction of chemical oxygen demand: The aqueous solution of dye exhibited $\lambda_{\max }$ in the visible region of spectrum at the wavelength of $545 \mathrm{~nm}$. The results shown in Figs. 1 and 2 illustrate the decrease in colour intensity was up to 10,16 and $18 \%$ while chemical oxygen demand reduction was up to 7,11 and $15 \%$, when the aqueous solutions of dye having concentration (10 to $50 \mathrm{mg} / \mathrm{L}$ ) were exposed to UV radiation for 20,40 and $60 \mathrm{~min}$, respectively. The results also indicate that the efficiency of dye degradation is less due to partial fragmentation. The attributed fact behind these findings is of quantitative nature that UV radiation has insufficient energy for the complete ionization and degradation of organic structure of dye which

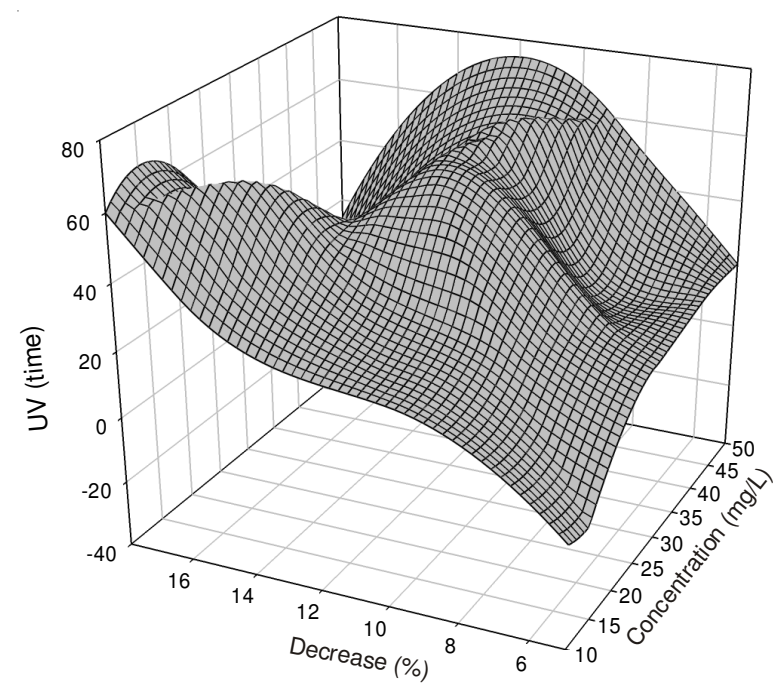

Fig. 1. Effect of UV radiation on absorbance of Reactive violet 1 dye

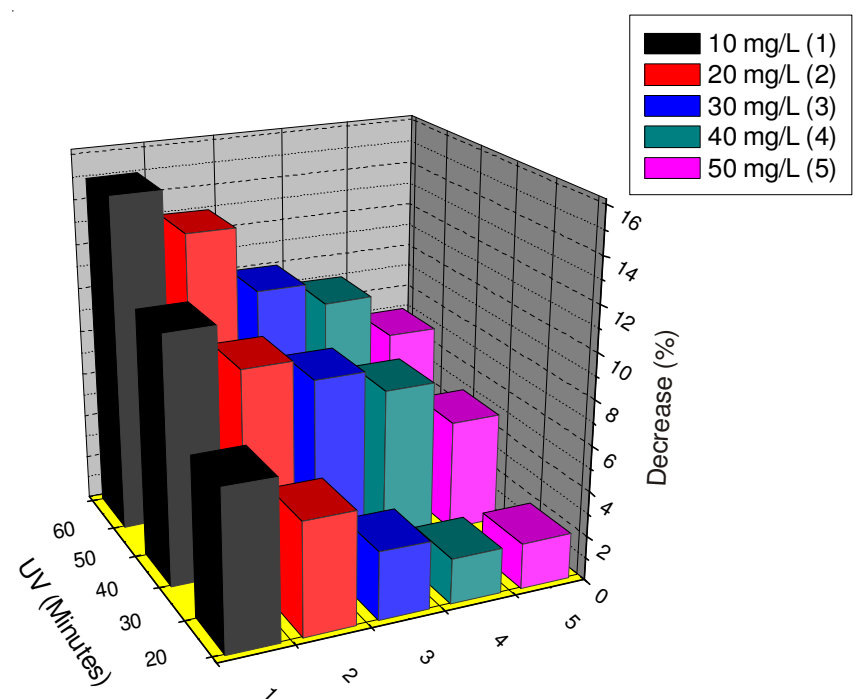

Fig. 2. Effect of UV radiation on chemical oxygen demand reduction of Reactive violet 1 dye

can not significantly reduce chemical oxygen demand values. It is also reported repeatedly that in most of the cases the treated dye solution regain the colour after UV treatment and this phenomenon was also observed in present study ${ }^{8}$.

Effect of $\mathrm{H}_{2} \mathrm{O}_{2}$ on absorbance and reduction of chemical oxygen demand: The treatment of aqueous solutions of dye has been carried out by $\mathrm{H}_{2} \mathrm{O}_{2}$, which is a powerful oxidant used as colour bleaching agent. It is usual treatment of dye bath effluents to make it reusable ${ }^{9,10}$. The decrease in absorbance was observed to $23,34,44,55$ and $65 \%$, while chemical oxygen demand reduction was found to $9,14,17,21$ and $25 \%$, when 5-25 $\mathrm{mM} \mathrm{H}_{2} \mathrm{O}_{2}$ was added in the dye solutions as shown in Figs. 3 and 4. The reduction in observed chemical oxygen demand was less as compared to colour removal of dye solutions since the colour removal occurred as chromophoric group disappeared while chemical oxygen demand reduction took place when the dye molecule split into low molecular weight carboxylic acid, carbon dioxide and water, etc..$^{8,11}$.

Effect of $\mathrm{UV} / \mathrm{H}_{2} \mathrm{O}_{2}$ on absorbance and reduction of chemical oxygen demand: The synergistic effect of UV radiation and hydrogen peroxide has successfully utilized to degrade the pollutants present in the wastewater. The results show that decrease in colour intensity was up to $38,67,85$, and $100 \%$, while the level of chemical oxygen demand was tested to

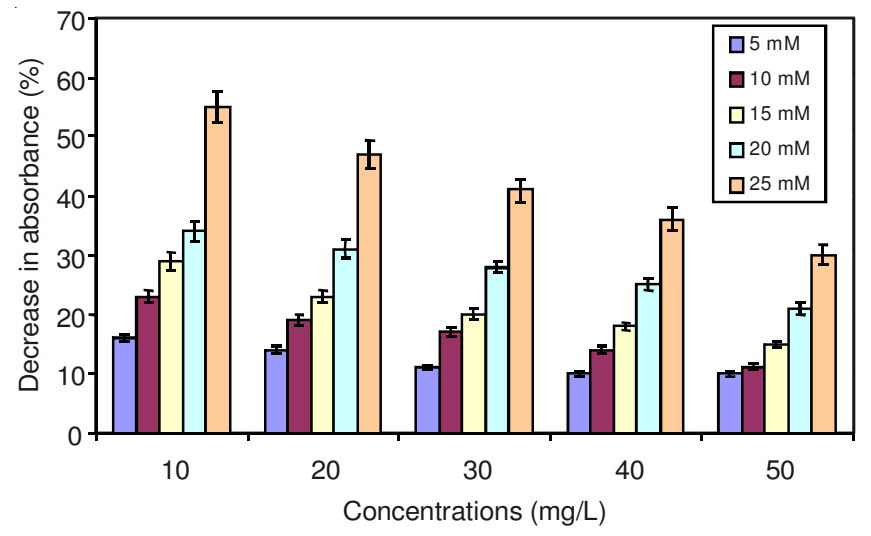

Fig. 3. Effect of $\mathrm{H}_{2} \mathrm{O}_{2}$ on absorbance of Reactive violet 1 dye 


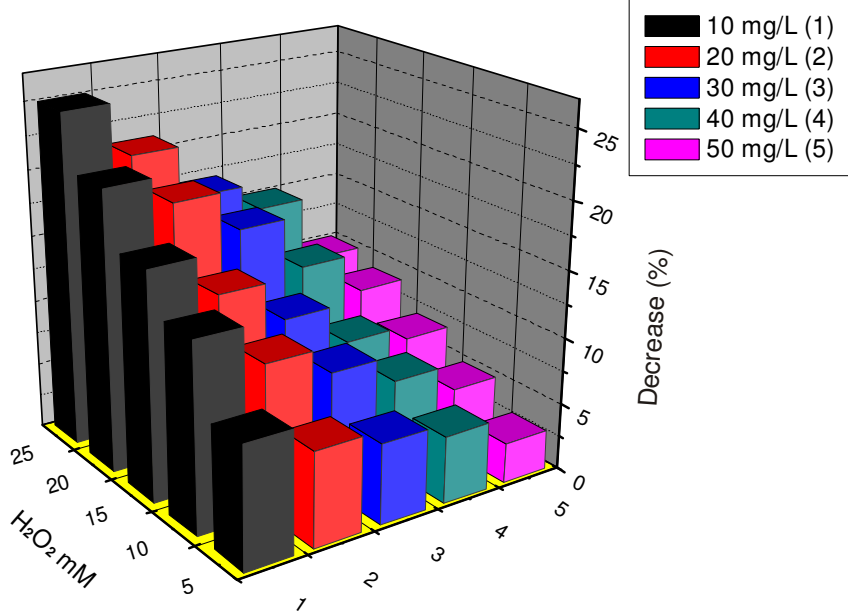

Fig. 4. Effect of $\mathrm{H}_{2} \mathrm{O}_{2}$ on chemical oxygen demand reduction of Reactive violet 1 dye

$19,30,41,48$ and $55 \%$ when the dye solution were treated with $\mathrm{H}_{2} \mathrm{O}_{2}$ having concentration 5-25 mM in combination with $60 \mathrm{~min}$. UV exposure time (Figs. 5 and 6). It is reported that $\mathrm{UV} / \mathrm{H}_{2} \mathrm{O}_{2}$ process effectively removes the chromophoric group of dye and subsequently extend this process until the complete mineralization of dye $\mathrm{e}^{12}$. The $\mathrm{UV}$ radiation $\left(\mathrm{OH}^{\circ}\right)$ interacts with $\mathrm{H}_{2} \mathrm{O}_{2}$ resulting in the homolysis of $\mathrm{H}_{2} \mathrm{O}_{2}$ to form hydroxyl radicals which have oxidation potential of $2.8^{10,11}$ react with pollutant non-selectively and degrade via oxidation reaction and ultimately convert into low molecular mass carboxylic acids, $\mathrm{CO}_{2}$ and $\mathrm{H}_{2} \mathrm{O}$, etc. The treatment by $\mathrm{UV} / \mathrm{H}_{2} \mathrm{O}_{2}$ is proficient for the reduction of colour intensity and chemical oxygen demand as a result of oxidative degradation of organic pollutants. It seems better than other advanced oxidation processes since it is rather simple, safe and green method ${ }^{13-16}$.

Fourier transform infrared spectroscopic studies (FTIR) studies: The FTIR profile of untreated reactive violet 1 dye before treatment shows specific vibration peaks at 3480 , $3430,3030,2366,1575,1545,1403$ and $1198 \mathrm{~cm}^{-1}$, respectively which has already been discussed in our previous study ${ }^{17}$.

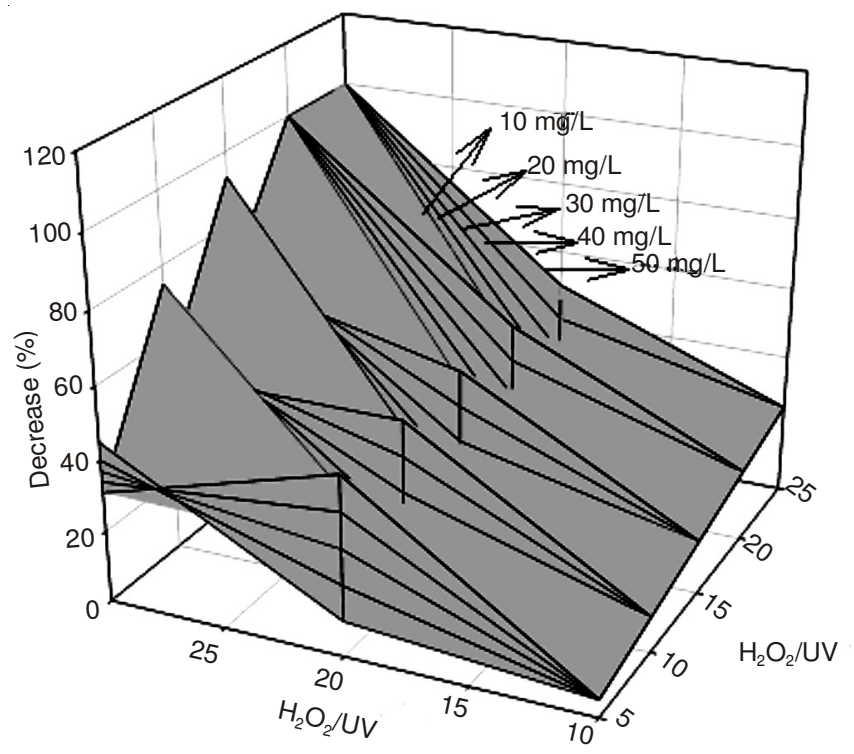

Fig. 5. Effect of $\mathrm{UV} / \mathrm{H}_{2} \mathrm{O}_{2}$ on absorbance of Reactive violet 1 dye

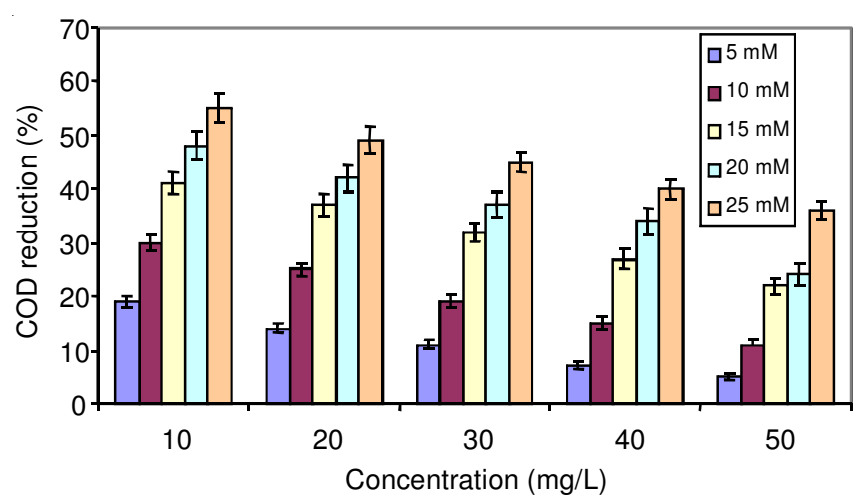

Fig. 6. Effect of $\mathrm{UV} / \mathrm{H}_{2} \mathrm{O}_{2}$ on chemical oxygen demand reduction of Reactive violet 1 dye

The FTIR profile of treated dye (Fig. 7) clearly indicates that almost all characteristics peaks such as $\mathrm{NH}, \mathrm{OH}, \mathrm{NH}_{2}, \mathrm{~N}=\mathrm{N}$, $\mathrm{C}=\mathrm{C}$ stretching as well $\mathrm{NH}$, symmetric $\mathrm{CH}$ bending vibrations, disappeared in $\mathrm{UV} / \mathrm{H}_{2} \mathrm{O}_{2}$ treated sample of dye having concentration $30 \mathrm{mg} / \mathrm{L}$. There are some minor peaks appeared at 3400 and $1400 \mathrm{~cm}^{-1}$ that might be due to the stretching vibration of $\mathrm{NH}$ group and the bending vibrations of $\mathrm{CH}$ group respectively. It is evident from the FTIR studies that the destruction of aromatic ring occurred due to advanced oxidation treatment as well as mineralization of dye molecule.

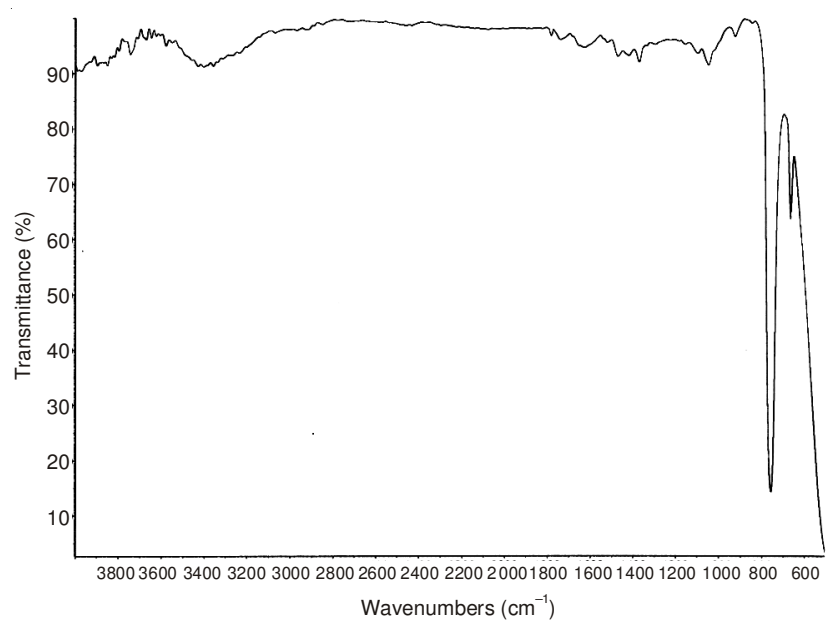

Fig. 7. FTIR profile of $(30 \mathrm{mg} / \mathrm{L})$ Reactive violet 1 dye treated with 25 $\mathrm{mM} \mathrm{H} \mathrm{H}_{2} \mathrm{O}_{2}$ in presence of $\mathrm{UV}$ radiation

GC-MS studies: For the confirmation of spectroscopic studies (UV/visible and FTIR spectrophotometry) and chemical oxygen demand analyses, the treated samples were further analyzed by GC-MS. The profile of treated sample clearly indicates the complete breakdown of dye molecules into $\mathrm{CO}_{2}$ and $\mathrm{H}_{2} \mathrm{O}$ as well as the fragments of low molecular mass species. Mass spectrogram clearly indicate the removal of dye molecule after the treatment of $\mathrm{UV} / \mathrm{H}_{2} \mathrm{O}_{2}$ support the assumption that advanced oxidation process is capable to degrade and mineralize the dyes leading to the formation of compounds having very low toxicity. The hydroxyl radicals generated during treatment practically attack on the dye molecule leading to its breakdown. The anticipated path way followed during reaction starts from the removal of azo groups present in the dyes, 
formation of dye intermediates that may be of aromatic carboxylic acids which further fragmented into low molecular mass carboxylic acids and finally degraded into $\mathrm{CO}_{2}$ and $\mathrm{H}_{2} \mathrm{O}$ as a results of mineralization of dye $\mathrm{e}^{18}$.

\section{Conclusion}

The advanced oxidation process using UV in presence of hydrogen peroxide is an effective method to treat the dye as a model compound and furthermore the treatment can be extended to real dyes and textile effluents also. With the help of this process the dyes can be completely decolourize and the level of chemical oxygen demand reduction was up to $55 \%$. The degraded end products will be monitored by FTIR and GC-MS which revealed that the dye molecules have completely degraded and mineralize. The present methods is a good option to treat the industrial effluents.

\section{ACKNOWLEDGEMENTS}

The authors are grateful to Mr. Muhammad Abbas, Director Harris Dyes and Chemical (Pvt.), Faisalabad, Pakistan for technical cooperation.

\section{REFERENCES}

1. E. Balanoskyand, F. Herrera, A. Lopez and J. Kiwi, Water Res., 34, 582 (2000).
2. M. Vautier, C. Guillard and J.M. Herrmann, J. Catal., 201, 46 (2001).

3. E. Rodriguez, R. Peche, J.M. Merino and L.M. Camarero, Environ. Eng. Sci., 24, 363 (2007).

4. N. Daneshvar, M. Rabbani, N. Modirshahla and M.A. Behnajadya, Radiat. Phys. Chem., B118, 155 (2005)

5. M. Behnajady, A.N. Modirshahla and H. Fathi, J. Hazard. Mater., B136, 816 (2006)

6. M. Sanchez, H. Wolfger and N. Getoff, Radiat. Phys. Chem., 65, 611 (2002).

7. A.S. Ozen, V. Aviyente and R.A. Klein, J. Phys. Chem. A, 107, 4898 (2003).

8. H.Y. Shu and M.C. Chang, Dyes Pigm., 70, 31 (2006).

9. A. Uygur and E. Kok, J. Soc. Dyers Colour., 115, 350 (1999).

10. A. Uygur, Color. Technol., 117, 111 (2001).

11. C.R. Huang and H.Y. Shu, J. Hazard. Mater., 41, 47 (1995).

12. G.M. Colonna, T. Caronna and B. Marcandalli, Dyes Pigments, 41, 211 (1999).

13. I.A. Alaton, I.A. Balcioglu and D.W. Bahnemann, Water Res., 36, 1143 (2002).

14. S. Esplugas, J. Gimenez, S. Contreras, E. Pascual and M. Rodriguez, Water Res., 36, 1034 (2002).

15. A. Aleboyeh, Y. Moussa and H. Aleboyeh, Dyes Pigments, 66, 129 (2005).

16. E. Rodriguez, R. Peche, J.M. Merino and L.M. Camarero, Environ. Eng. Sci., 24, 363 (2007).

17. M. Muneer, I.A. Bhatti, M. Iqbal and M. Ather, J. Chem. Soc. Pak., 34, 787 (2012).

18. C. Hu, J.C. Yu, Z. Hao and P.K. Wong, Appl. Catal. B, 42, 47 (2003). 